\title{
The Influence of Height and Health on Income-An Empirical Study Based on CFPS Data
}

\author{
Xin Sun \\ School of Economics, Shanghai University \\ Shanghai, China \\ E-mail:471851821@qq.com
}

\begin{abstract}
In this paper, the Chinese family tracking survey (CFPS) data as well as the OLS method were used to estimate the impact of height, weight, and health on income, meanwhile, the intelligence was regarded as a proxy variable for the measurement of individual ability. The results obtained show that height and health level have a significant positive effect on income; As parts of human capital, height and health increase the intake of nutrients and the return on investment; The higher the social security provided by the government, the healthier of all the workers; The entire labor market increases productivity.
\end{abstract}

\section{Keywords-Height health; Income level; Human capital}

\section{RESEARCH BACKGROUND}

Since the beginning of the 21 st century, China's economy has maintained a high growth rate, making China's economy surpassing Japan and ranking second in the world. Human capital, one of the elements of economic growth, has played an important role in the process of economic development. In the change of industrial structure, China has gradually moved from a labor-intensive industry to a capital-intensive industry. This important strategic transformation has taken place. This caused a profound change in the structure of the labor market. At the same time, the establishment and further improvement of the socialist market economic system gradually shifted from the form of resource allocation dominated by government intervention to the form in which the market played a decisive role in economic development and resource allocation. As a result, a market-based wage decision mechanism has been formed, that is, macro wages are determined by the intersection of the labor market supply curve and the demand curve. According to Yin Chengji, a spokesperson for the Ministry of Human Resources and Social Affairs, in the current circumstances, the salary level of employees in China's enterprises mainly depends on four factors: First, the relationship between supply and demand in the labor market, and the level of human capital such as the education level of the workers themselves; Labor productivity and the quantity and quality of labor provided by the laborers themselves. Third, laborers, trade unions and enterprises determine the mechanism for wages through negotiation. Fourth, the government regulates the distribution of wages necessary for enterprises, such as the reasonable determination of the minimum wage. From his point of view, we can see that the level of education as a part of human capital also has an increasingly important impact on the economy. The role of individual ability as an important part of human capital in the level of wages is also gradually magnified. From a more microscopic perspective, the health and height of workers as an important part of human capital are less valued in the study of domestic labor economics than education. Wages are the main source of residents' income. The strength of human capital has a direct impact on the wage level and has an impact on household disposable income. This in turn affects the level of consumption in the household sector. Consumption, investment, and net exports drive economic development in China. Therefore, the level of wages will even have an impact on the growth of the entire economy.

Previous scholars have also done similar research. Li Liying used the Heckman model to estimate the impact of height and body mass index on wages of non-agricultural employment residents using the 2009 China Nutrition and Health Survey data [13Lv Xiaokang analyzed the influence of his body shape on wages from the perspective of evolutionary psychology. He used the data from the Chinese Family Health Survey (CHNS2009) to study the impact of his height, weight, and BMI values on his body's salary. The results of the quantile regression indicate that body size has a statistically significant effect on women's wages, and that the effect on men's wages is not significant, and that this effect occurs only in women with medium wage levels [2]. Ning Jiaqi also used the body mass index (BMI) as a measure of health to study the relationship between the health status of Chinese residents and the wage level. He used data from the 2012 China General Social Survey (CGSS) to analyze the impact of health conditions. The channels of salary levels have found that good health conditions have positive effects on individual wages, and lifestyle is an important factor affecting health status. [3] Wang Peng used Chinese health and nutrition survey data to introduce healthy human capital into the wage decision model, and conducted an empirical analysis of the impact of healthy human capital on wages in the labor market in China and gender wage differences. [4]Gao Wen uses the household survey data of 12 cities such as Shanghai and uses the OLS and instrumental variables method to return the extended Mincer wage equation, which shows that height has a positive influence on the wages of workers. [5]Based on the above research, this paper uses the large sample micro survey data to empirically study the wage effect of Chinese workers and conducts empirical analysis through gender classification, the results of the regression of different genders were analyzed. For this unobservable variable, it may cause inconsistency in 
the estimation results. So this article uses the intelligence level as a proxy variable for the ability, to estimate the impact of height and health on wage levels.

\section{DATA DESCRIPTION}

This article uses data from the 2012 China Family Tracking Survey (CFPS). It is a survey conducted by the China Social Science Survey Center (ISSS) of Peking University, which aims to collect data on three levels of individuals, families, and communities. Social, economic, demographic, educational, and health changes are major social science projects that provide data for academic research and policy decisions. The data investigated the subjects of Chinese families and individuals and adopted a questionnaire survey. The object of this paper is the 16-year-old and above employees in the industry, the final application of a total of 7168 data, of which 2795 were women, accounting for $39 \%$, a total of 4373 men, accounting for $61 \%$; on the whole, where $\mathrm{y}$ The average monthly income of respondents was 1,834 yuan, and the income of all individuals was between 1 yuan and 50,000 yuan. It can be seen that the standard deviation of data is very large, which means that the income gap between individuals is large, and the average monthly income of men is 2059 yuan, higher than women's 1497 yuan, and the income gap between men than women; height unit is centimeters, the average height in all samples is 166.64 centimeters, in which the average height of men is 170.65 centimeters, the average height of women is 160.04 centimeters; The unit is jin, and the average weight in the sample is 126.93 pounds, of which the average weight of males is 136 pounds and the average weight of females is 112.06 pounds; Intel represents the intelligence level and is the proxy variable for personal ability in this article, which is divided into 1 to 7 different grades. The lowest is 1 and the highest is 7 . From the standard deviation, it can be seen that the level of intelligence is not much different; the number of years of education in the sample varies from 0 to 22 years, and the average number of years of education is 20.29 years. . Subject to years of schooling in 1012 was slightly lower than women in 1054; the average work experience was in 1107, with an average work experience of men than women; Specific statistics such as mean, standard deviation, minimum and maximum values in the table below.

TABLE I. DESCRIPTIVE STATISTICS OF VARIABLES

\begin{tabular}{|c|c|c|c|c|c|c|c|c|c|c|c|c|}
\hline \multirow[b]{2}{*}{$\begin{array}{c}\text { Variable } \\
\text { name }\end{array}$} & \multicolumn{4}{|c|}{ Overal } & \multicolumn{4}{|c|}{ Male } & \multicolumn{4}{|c|}{ Female } \\
\hline & Mean & $\begin{array}{l}\text { Maximu } \\
\mathrm{m} \text { value }\end{array}$ & $\begin{array}{l}\text { Minimu } \\
\mathrm{m} \text { value }\end{array}$ & $\begin{array}{l}\text { Standard } \\
\text { deviation }\end{array}$ & Mean & $\begin{array}{c}\text { Maximum } \\
\text { value }\end{array}$ & $\begin{array}{l}\text { Minimu } \\
\mathrm{m} \text { value }\end{array}$ & $\begin{array}{l}\text { Standard } \\
\text { deviation }\end{array}$ & Mean & $\begin{array}{c}\text { Maximum } \\
\text { value }\end{array}$ & $\begin{array}{l}\text { Minimu } \\
\text { m value }\end{array}$ & $\begin{array}{l}\text { Standard } \\
\text { deviation }\end{array}$ \\
\hline $\mathrm{y}$ & 1834.64 & 50000 & 1 & 2008.80 & 2059.98 & 50000 & 1 & 2280.54 & 1497.30 & 30000 & 20 & 1397.29 \\
\hline height & 166.64 & 197 & 120 & 7.52 & 170.65 & 197 & 146 & 5.81 & 160.04 & 180 & 120 & 4.89 \\
\hline health & 5.67 & 7 & 1 & 1.01 & 5.67 & 7 & 1 & 1.01 & 5.67 & 7 & 1 & 1.01 \\
\hline intel & 5.37 & 7 & 1 & 1.09 & 5.36 & 7 & 1 & 1.08 & 5.39 & 7 & 1 & 1.09 \\
\hline educ & 10.29 & 22 & 0 & 3.96 & 10.12 & 22 & 0 & 3.85 & 10.54 & 22 & 0 & 4.11 \\
\hline $\exp$ & 11.07 & 2013 & 0 & 53.53 & 11.10 & 2013 & 1 & 31.60 & 8.84 & 2013 & 1 & 39.21 \\
\hline
\end{tabular}

\section{EMPIRICAL ANALYSIS}

By directly observing the variables in the data and eliminating some of the outliers, the observations show that people with higher heights also correspond to higher monthly wage levels, and that they generally assume a top-to-bottom distribution. People with higher heights are more likely to be interviewed by the interviewer in appearance and form, which helps to increase their bargaining power in wage contracts and social advantages in the actual work process. Some people with lower heights even have lower weight. When looking for a job, it is simply not suitable for the interview conditions of certain companies, so that the job with lower wages can be selected. At the same time, people with higher health levels also correspond to higher monthly wage levels because good health levels can increase the strength of physical labor and the efficiency of mental work, as well as increase the concentration in the work process. Reducing the psychological pressure caused by the lack of health conditions and the nature of some jobs require employees to have specific conditions in their health level. The company will regularly allow employees to go to the hospital for necessary health checks. However, this is only an intuitive observation. This intuitive observation cannot simultaneously control the impact of individual variables such as individual's weight, years of schooling, ability, and work experience on wages. For example, a person with a heavier body weight may not be able to meet the conditions for a highincome job. Even if the conditions are met, the work efficiency may be affected by the disease caused by obesity. The number of years of schooling affects the individual's academic qualifications. From previous experience, he has a higher degree. The wage level of a person is generally higher than that of a person with a lower level of education. The wage difference between the two sides may not gradually decrease with the increase of the number of years of work. With the development of science and technology, individuals with higher academic qualifications are more able to Adapt to highskilled and emerging jobs with higher salary levels, such as the 
computer industry, biotechnology, smart manufacturing, scientific research, etc.; individual capabilities are reflected in many aspects such as learning, management, socialization, etc. We generally think that there are relatively high Competitors are more likely to obtain higher wages, those with poorer ability have less chances to obtain higher wages, and work experience is an important individual characteristic in the interviewing conditions of enterprises, and it is also an important factor in achieving the purpose of the work. Because people who have more work experience are better able than those who have less work experience meet the business requirements of the post, some companies will not even consider recent college graduates. In summary, intuitive observations of the effects of variables such as uncontrollable weight, years of education, ability, and work experience on wages are needed. Therefore, we need to use econometric methods to further empirically analyze the relationship between height, health, and wages.

The method used in this paper is the least-squares method (OLS) estimation, using the extended Mincer equation to regress wages, and its regression model is:
$\mathrm{Y}=\beta 0+\beta 1$ height $+\beta 2$ weight $+\beta 3$ health $+\beta 4$ educ + $\beta 5 \exp +\beta 6 \exp 2+\beta 7$ intel $+\beta 8$ gender $+\varepsilon$

Among them, height is height, weight is weight, and health is health level. In the text, one person's health level is divided into seven grades from 1 to 7 , of which 1 is the worst, 7 is the best, educ is the number of years of education, exp For work experience, this paper uses a method similar to the Mincer equation, adding the square of the work experience because there is a maximum effect of work experience on wages. Because individual ability is an unobservable factor, but personal ability has a direct impact on wages, so this article only uses the intelligence level as an agent variable of individual ability, can substitute the level of individual ability similarly, the Chinese tracking survey data on the measured intelligence Levels are divided into seven levels, with 1 being the worst and 7 being the best. The variable gender represents gender, 1 is male, and 0 is female. Because of different physical conditions, this article first returns to the overall value including gender, and then returns to male and female respectively. The regression results are as follows.

TABLE II. OVERALL AND SEX-SPECIFIC OLS REGRESSION ANALYSIS RESULTS

\begin{tabular}{|c|c|c|c|c|c|c|}
\hline \multirow{2}{*}{ Variable name } & \multicolumn{2}{|c|}{ Overal } & \multicolumn{2}{c|}{ Male } & \multicolumn{2}{c|}{$\begin{array}{c}\text { Semale } \\
\text { deviation }\end{array}$} \\
\cline { 2 - 7 } & coefficient & Standard deviation & coefficient & Standard deviation & coefficient \\
\hline _cons & $-3207.980^{* * *}$ & 701.530 & $-2963.244^{* * *}$ & 1034.820 & $-2911.964^{* * *}$ & 853.213 \\
\hline height & $15.482^{* * *}$ & 4.714 & $14.148^{* * *}$ & 6.567 & $19.090^{* * *}$ & 5.735 \\
\hline weight & 2.907 & 1.278 & $4.168^{*}$ & 1.742 & $-2.037^{*}$ & 1.700 \\
\hline health & $50.230^{* * *}$ & 13.940 & $58.224^{* *}$ & 14.705 & $32.866^{* * *}$ & 9.090 \\
\hline educ & $102.741^{* * *}$ & 6.278 & $106.948^{* * *}$ & 9.384 & $93.763^{* * *}$ & 6.838 \\
\hline exp & $6.796^{* * *}$ & 2.572 & $5.302^{*}$ & 3.510 & $12.677^{* * *}$ & 3.320 \\
\hline exp2 & $-0.003^{* * *}$ & 0.001 & $-0.002^{*}$ & 0.002 & $-0.006^{* * *}$ & 0.002 \\
\hline intel & $88.953^{* * *}$ & 27.917 & $107.005^{* * *}$ & 40.058 & $56.758^{* *}$ & 32.031 \\
\hline gender & $357.461^{* * *}$ & 66.592 & & & \\
\hline Adjusted $\mathrm{R}^{2}$ & \multicolumn{2}{|c|}{0.083} & & & \\
\hline
\end{tabular}

From the overall regression results in Table 2, it can be seen that except for the number of years of education, work experience has a significant effect on wages. For every one centimeter increase in height, the average monthly wage will increase by 15 yuan, which is very significant at the $1 \%$ level. The level of health also has a significant impact on wages. Every level of health is raised by one level, and the average monthly income is increased by 50 yuan. This is consistent with the positive effects mentioned earlier, namely that the coefficient of health and height is positive, verifying the previous expectations. The regression result also found another problem: the coefficient of gender is 357.46 and is very significant, which means that under the same conditions, men will be 357 yuan higher than women's average monthly wage.

Observing the male and female laborers respectively, the impact of their height on wages is very significant. Among them, the return rate of female height is slightly higher than that of male workers, indicating that for women, height will have more advantages in job search. . For weight, the coefficient of the two is the opposite. For men, if the body weight is increased by 1 pound, the monthly salary will increase by 4 yuan, while for women, the weight will decrease by 1 pound. Wage will increase by two yuan, although this coefficient is only significant at the $10 \%$ level, but it can also explain some problems. Since there is no occupation in this regression, there may be occupational differences between men and women. Areas where men work may be biased towards manual labor, and women may be more important in the industry. For the variable health, male workers return healthier than women, which may also be related to careers. This empirical result is similar to the results of an empirical study of similarly applied OLS methods for some developing countries (eg, Schultz, 2002). [6]The regression results also show that the number of years of education, work experience, and personal ability have significant levels of wages, and the direction of influence is also completely consistent with the theoretical expectations. 


\section{CONCLUSION}

This article focuses on the impact of height and health on wages. Height and health are human capital. Human capital occupies a large proportion in labor economics. With the rise of human capital research, more and more scholars pay attention. It has invested in human capital. People with higher heights usually have higher advantages in terms of strength, speed, etc., which may lead to higher productivity, and employers naturally provide higher wages. This article makes use of the data from the Chinese family follow-up survey and uses the OLS regression method to estimate the height and health return on wages. This effect is also very significant. With other conditions unchanged, the height of the male is increased by one centimeter. The monthly salary will increase by 14.1 yuan. For every one centimeter increase in female worker's height, the monthly salary will increase by 19 yuan. For every level of health improvement, the monthly salary will increase by 50 yuan. This is understandable because no employer wants to hire the body. Bad staff.

The conclusions obtained in this paper can provide individuals and governments with some policy recommendations. For individuals, Nutritional intake should be increased from childhood or adolescence. Childhood nutritional intake and health care status are significantly related to the height of adult workers. In their youths, they should strengthen physical training and further increase nutritional intake, and provide mental health counseling and counseling in their teenage years. It can be seen that investment in human capital for height and health will increase the wage rate of return in adulthood, and in turn generate a return to the lucrative labor market. This investment in human capital is very worthwhile. . For the government, it should increase social security, and healthy human capital investment has significant positive externalities. The government's focus on residents' health status and physical level can generally increase the level of social labor productivity, so as to increase residents' income, ring about more social returns, and ultimately improve the overall economic level of a country.

\section{REFERENCES}

[1] Liying LI, Qianqian TIAN. "Study on the Impact of Health Status on Residents' Wages - Based on China Nutrition and Health Data", Journal of Henan University of Technology, No. 1, 2013.

[2] Xiaokang Lü, Lin Xing. "Effect of Body on Salary: Perspective of Evolutionary Psychology", Journal of Northwest Normal University (Social Sciences Edition), 2017(1).

[3] Jiaqi Ning, "Study on the Effect of Health Status on Wage Level", Research on Financial Issues, No. 1, 2016.

[4] Peng Wang, Guoen Liu. "Health human capital and gender wage differences", Southern Economy, No. 9, 2010.

[5] Wen Gao. "Health Human Capital Investment, Height and Salary Remuneration - An Empirical Study of 12 Urban Household Survey Data", China Population Science, 3rd issue, 2009.

[6] Schultz, "Wage Gains Associated with Height as a form of Health Human Capital". The American Economic Review. 92 (2): 349-353 